\title{
Treatment of facial lipoatrophy, morphological asymmetry, or debilitating scars with the hyaluronic acid dermal filler Princess ${ }^{\circledR}$ FILLER
}

This article was published in the following Dove Press journal: Clinical, Cosmetic and Investigational Dermatology

\author{
Daisy Kopera' \\ Zrinka Ivezic-Schoenfeld ${ }^{2}$ \\ Ira G Federspiel ${ }^{2}$ \\ Doris Grablowitz \\ Benjamin Gehl ${ }^{4}$ \\ Martin Prinz ${ }^{2}$ \\ 'Department of Dermatology, Medical \\ University of Graz, Graz, Austria; \\ ${ }^{2}$ Croma-Pharma $\mathrm{GmbH}$, Leobendorf, \\ Austria; ${ }^{3}$ Medical Aesthetic Centre \\ Vienna, Vienna, Austria; ${ }^{4}$ Private \\ Practice, Vienna, Austria
}

Purpose: The aim of this study was to evaluate the effectiveness and safety of hyaluronic acid (HA) dermal filler when used in the face for medical reconstructive purposes.

Patients and methods: Adult patients with moderately severe facial lipoatrophy (FLA), morphological asymmetry (MA) of the face, or debilitating scars (DS) on the face were included in a prospective, noncomparative, multicenter, postmarket clinical follow-up study. All patients were treated with an HA filler (Princess ${ }^{\circledR}$ FILLER), which was injected intradermally on study Day 1, with optional touch-up 2 weeks later. The effectiveness of the treatment was evaluated at Weeks 4 and 24, using a six-grade scale ranging from "excellent" to "worsening". The assessments were conducted by both the investigator and the patient and, at Week 4, by the independent photography reviewer as well. Adverse events were collected at each visit.

Results: Fifty-three patients were included in the study (FLA 23, MA 17, and DS 13), and 46 patients completed a 6-month follow-up (FLA 20, MA 15, and DS 11). At Week 4 (primary endpoint), the overall treatment success rate was 100\% (FLA), 100\% (MA), and 94\% (DS), based on assessments made by the investigator, patients, and the independent reviewer, respectively. In most patients ( $95 \%)$, the effect was sustained over 6 months. Treatment-related adverse events were reported in five patients $(9 \%)$ and included injection site hematoma, injection site pain, and headache.

Conclusion: Dermal filling with HA gel is a viable treatment option for the correction of various deformities of the face resulting from FLA, MA, or DS.

Keywords: clinical study, hyaluronic acid, dermal filler, Princess ${ }^{\circledR}$ FILLER, effectiveness, safety

\section{Introduction}

Soft tissue fillers are nowadays widely used in cosmetic dermatology and esthetic surgery for the facial rejuvenation or redefinition of facial contours. Although various fillers are available on the market, hyaluronic acid (HA) gels are most popular. In USA only, they were used in almost 2.5 million esthetic procedures in 2016, representing over $90 \%$ of procedures involving any soft tissue filler. ${ }^{1}$ Such wide-spread use of HA fillers is driven by their versatility, ease of administration, predictable effectiveness, safety track record established during decades of use, and nearly no downtime after the treatment. ${ }^{2,3}$

Esthetic procedures are typically undertaken to remove or reduce the signs of aging or to increase the attractiveness of an otherwise healthy face. There is, however, a range of pathological conditions, which may result in an "abnormal", asymmetrical appearance of the face with consequent emotional suffering of the patient, psychosocial
Correspondence: Martin Prinz Croma-Pharma GmbH, Industriezeile 6, 2100 Leobendorf, Austria

Tel +43226268468300

Fax +43226268468165

Email martin.prinz@croma.at 
dysfunction, and reduced quality of life. ${ }^{4-6}$ Some of these, such as facial lipoatrophy (FLA) and atrophic skin scars, are characterized by reduced tissue volume, which can be restored by injecting a soft tissue filler. ${ }^{7,8}$ Similarly, in case of morphological asymmetry (MA) of the face, increasing the volume of visually hypoplastic areas with a filler is a simple and minimally invasive solution for harmonizing the appearance. With the exception of HA use for the correction of FLA in patients with HIV infection, which was studied in several clinical trials, ${ }^{9-13}$ literature data on the effectiveness and safety of HA fillers in the treatment of other facial pathologies are fairly limited. Furthermore, available HA fillers differ in physical properties and tissue residence time, ${ }^{14}$ parameters that may influence the overall performance.

The present study was undertaken to evaluate the effectiveness and safety of Princess ${ }^{\circledR}$ FILLER, a marketed HA dermal filler, when used in routine practice for medical reconstructive purposes in patients with FLA, MA of the face, or debilitating scars (DS). This filler is a low viscosity gel of cross-linked HA, designed for injection into the midto-deep dermis. The expected lifetime upon implantation is 6-9 months.

\section{Patients and methods}

This was a prospective, noncomparative, multicenter, postmarket clinical follow-up study of a European conformitymarked dermal filler Princess ${ }^{\circledR}$ FILLER (ClinicalTrials.gov, NCT03050723). The study consisted of four visits, performed at baseline and 2, 4, and 24 weeks thereafter. Up to 60 patients with FLA, MA, or DS were to be included to obtain 24-week follow-up data from 10 to 20 patients per indication.

The trial was conducted at three dermatology clinics in Austria, from December 2016 to July 2017, in line with the ISO 14155 standard and ethical principles of the Declaration of Helsinki. The protocol and relevant study documents were reviewed and approved by the ethics committee of the Medical University of Graz and the ethics committee of the city of Vienna. Written informed consent was obtained from each patient prior to inclusion in the study. Individual participant data that underline results reported in this article, after deidentification, are contained within this article.

\section{Study population}

Adult patients suffering from FLA of moderate severity (grades 2-3 according to the Ascher's scale ${ }^{15}$ and unrelated to aging), MA of the face, or at least one DS on the face were included. The defect had to be correctable by a dermal filler in the investigator's opinion, the skin on the face healthy (with the exception of visible atrophic acne scars), and the patient willing to take part in the study and abstain from any other esthetic or surgical procedures in the treatment area over the following 6 months.

Exclusion criteria comprised pregnancy, breastfeeding, or unwillingness to use contraception throughout the clinical investigation (for women of child-bearing potential only); previous allergic reaction or hypersensitivity to HA; a history or presence of hypertrophic scars, keloids, or pigment disorders; any autoimmune or connective tissue disease, or current treatment with immune therapy; a silicone implant or nonabsorbable tissue filler in the area targeted for intervention, or treatment with any HA filler in the previous 6 months; presence of infectious, inflammatory, or proliferative lesions in the area targeted for intervention, including a history of herpes zoster or recurrent herpes simplex; current treatment with anticoagulant or antiplatelet drugs, unless the risk of bleeding has been discharged; current participation in another clinical trial, or treatment with any investigational drug or device within 30 days prior to enrolment; and any other disease or condition, which in the investigator's opinion represented a safety risk for participation in the study. Institutionalized persons with legally limited civil rights were excluded as well.

\section{Intervention}

All patients were treated with an HA dermal filler, containing $23 \mathrm{mg} / \mathrm{mL}$ of HA produced by Streptococcus equi bacteria and cross-linked using 1,4-butanediol diglycidyl ether (Princess $^{\circledR}$ FILLER, Croma-Pharma GmbH, Leobendorf, Austria). Pretreatment with a topical anesthetic was optional. At the baseline visit, the filler was injected into the mid to deep dermis, in amount needed to achieve a desired level of correction. A touch-up was allowed after 2 weeks and was performed at the investigator's discretion. The total volume of the filler was limited to $10 \mathrm{~mL}$ per patient.

\section{Outcome assessments}

At Weeks 4 and 24, the effectiveness of the treatment was evaluated by the investigator and separately by the patient using a six-grade scale presented in Table 1. At Week 4, the effectiveness was also evaluated by an independent reviewer using patient photographs and the same scale. The primary effectiveness endpoint was the proportion of patients with successful treatment outcome at Week 4 based on the investigator's assessment, where success was defined as an excellent, good, or moderate correction of the defect. Treatment success rates derived from other assessments described earlier, overall 
Table I Treatment outcome grading

\begin{tabular}{|l|l|}
\hline Outcome & Description \\
\hline Excellent & Significant improvement in patient's appearance vs baseline, with complete or almost complete correction of the treated defect \\
\hline Good & Significant improvement in patient's appearance vs baseline, with achieved correction in line with expected result \\
\hline Moderate & Obvious improvement in patient's appearance vs baseline, with achieved correction slightly below the expectation \\
\hline Slight & Minimal improvement in patient's visual appearance vs baseline \\
\hline No effect & No change in patient's visual appearance vs baseline \\
\hline Worsening & Deterioration of patient's visual appearance vs baseline \\
\hline
\end{tabular}

Note: Treatment success is defined as an excellent, good, or moderate correction of the defect.

and stratified by indication, were secondary endpoints. The tolerability and safety were evaluated based on the occurrence of adverse events, which were collected at each visit.

\section{Statistics}

The sample size of 60 patients was arbitrarily selected, based on the anticipated feasibility of recruitment, and was sufficient to provide robust estimation of the primary endpoint. With a sample size of 60 , a two-sided $95 \%$ CI for a single proportion using the large sample normal approximation extended 0.076 from the observed proportion for an expected proportion of 0.900 . The primary population for data analysis was the safety population (SP), defined as all patients who received the investigational device and had at least one posttreatment assessment. The effectiveness was also analyzed in the per-protocol population (PP), defined as all patients who received the investigational device and have completed the study without a major protocol deviation. All data were analyzed using descriptive statistics. For the primary endpoint and other treatment success rates, percentages were calculated based on the number of patients treated (intent-to-treat approach with missing data accounted as nonsuccess) and 95\% CIs were derived using the Pearson-Clopper interval. ${ }^{16}$ In addition, for individual grades of treatment outcome, percentages were calculated based on the number of observations.

\section{Results}

\section{Patient baseline characteristics and disposition}

A total of fifty-three patients were included in the study: 23 patients with FLA, 17 patients with MA, and 13 patients with DS. All patients were white (non-Hispanic or Latino), and all but one with DS were women. The mean age of the patients was 48.1 years (range 23-76 years) and was slightly higher in those with FLA (mean 48.2 [range 26-75] years) or asymmetry (51.7 [34-76] years) than those with scars (43.0 [23-75] years). Among patients with FLA, 11/23 (48\%) patients suffered from grade 2 and 12/23 (52\%) patients suffered from grade 3 according to Ascher's scale (grades $1-5$, with 5 being the most severe). In patients with MA, the severity of volume deficit on the left side, compared to the respective area on contralateral side, was mild in $4 / 17$ $(23 \%)$ cases, moderate in $11 / 17$ (65\%) cases, and severe in $2 / 17(12 \%)$ cases; on the right side, it was mild in $8 / 17$ $(47 \%)$ cases and moderate in $9 / 17(53 \%)$ cases. The severity of scars was not graded. In 11/13 (85\%) patients, the scars were hypotrophic, and in 2/13 (15\%) patients, the scars were hypertrophic; none was calcified.

In a total of nine (17\%) patients, including 3/23 (13\%) patients with FLA, 5/17 (29\%) patients with asymmetry, and $1 / 13(8 \%)$ patients with scars, the defect had previously been treated with an HA filler. In two of these patients, it could not be ruled out that the treatment had occurred within 6 months prior to screening due to an incomplete treatment date (month and year only).

Of the 53 patients treated, all attended Week 2 visit, $51(96 \%)$ patients returned for Week 4 visit, and 46 (87\%) patients completed a 24-week follow-up. One patient was withdrawn from the study because of pregnancy, two patients withdrew consent, and four patients were lost to follow-up after Week 4 visit. All patients who took part in the study were included in the SP, and 44 (83\%) patients met all criteria for the PP. Major protocol deviations were related to missed visits due to premature termination, missed visit windows, and potential violation of the wash-out period for previous HA treatment as described earlier.

\section{Treatment details}

In most patients, the filler was applied bilaterally and into more than one area of the face (Table 2). At the initial application, $4.3 \mathrm{~mL}$ was injected on average, most commonly by serial puncture (in 30 patients; 57\%), followed by linear threading $(14 ; 26 \%)$, cross-hatching $(5 ; 9 \%)$, and serial threading $(4 ; 8 \%)$. Serial puncture was a leading injection technique across the indications, used in 11/23 (48\%), 9/17 
(53\%), and 10/13 (77\%) patients with FLA, asymmetry, and scars, respectively. A touch-up was performed in 37 (67\%) patients, and a total of $6 \mathrm{~mL}$ of the filler was administered on average (Table 3 ). The treatment was generally performed without local anesthesia; anesthetic cream was applied only in one patient who suffered from FLA.

\section{Treatment effectiveness}

In the SP, the treatment success rate at Week 4 was $96.2 \%$ (51/53; two-sided 95\% CI 87.0-99.5); exactly the same result was obtained with both the investigator and the patient assessments. In the independent reviewer's opinion, the treatment was successful in $91 \%$ of patients $(48 / 53 ; 95 \%$ CI: 79.3-96.9). At Week 24, success rates were lower $(83 \%$ by the investigator [44/53; 95\% CI: 70.2-91.9] and $81 \%$ by patients' self-assessment [43/53; 95\% CI: 68-90.6]), primarily because drop-outs were accounted as treatment failures. When success rates were calculated based on the number of actual observations, these reached 94\%-100\% at Week 4 , depending on the evaluator, and 94\%-96\% at Week 24 (Figure 1). Treatment results are also illustrated in Figures 2-4. Results obtained in the PP were generally similar and are not presented for this reason.

\section{Adverse events}

Adverse events were reported in $11(21 \%)$ patients. Treatment-related events occurred in the following five $(9 \%)$ patients: four patients with FLA and one patient with MA. Two patients had mild injection site hematoma, appearing 2-3 days after initial or touch-up treatment, respectively, and resolving within 3 weeks. Two additional patients had moderate injection site pain, one of them also reported a headache, and further one experienced headache only. These events occurred after touch-up and resolved within 2-4 days.

\section{Discussion}

This study has shown that various soft tissue defects of the face can be corrected successfully with the Princess ${ }^{\circledR}$ FILLER, an HA dermal filler. Princess ${ }^{\circledR}$ FILLER was approved in Europe in 2008 for lip augmentation and the correction of moderateto-severe facial wrinkles and folds. In 2015, the approval was extended to medical indications discussed here.

The three indications studied are diverse in terms of pathogenesis and clinical presentation but share a common denominator - a deficit in tissue volume. In FLA, the volume loss is due to the atrophy of facial adipose tissue and the disease is primarily manifested on cheeks, temples, and in the preauricular, orbital, and perioral regions. The underlying cause is known in some patients (eg, antiretroviral therapy in HIV-positive individuals, autoimmune connective tissue diseases, various lipodystrophy syndromes, and trauma), ${ }^{7,15}$ but in many, it remains unclear why slow physiological involution of facial fat pads takes a more aggressive course, resulting in pathological appearance. In contrast to FLA, volume deficit in depressed scars results from either inflammatory destruction of collagen fibers and subcutaneous fat, which typically occurs in atrophic acne scars, ${ }^{17}$ or physical loss of skin supporting structures during the insult, which preceded the scar. In MA of the face, volume deficit may be actual due to unilateral hypoplasia of various skin supporting structures,

Table 2 Overview of anatomic areas treated with the hyaluronic acid dermal filler Princess ${ }^{\circledR}$ FILLER

\begin{tabular}{|l|l|l|l|l|}
\hline Treatment area & $\begin{array}{l}\text { Overall } \\
(\mathbf{N}=\mathbf{5 3})\end{array}$ & $\begin{array}{l}\text { Facial lipoatrophy } \\
\mathbf{( N = 2 3 )}\end{array}$ & $\begin{array}{l}\text { Morphological asymmetry } \\
\mathbf{( N = 1 7 )}\end{array}$ & $\begin{array}{l}\text { Debilitating scars } \\
(\mathbf{N}=13)\end{array}$ \\
\hline Upper face, $\mathrm{n}(\%)$ & $18(34)^{\mathrm{b}}$ & $9(39)^{\mathrm{a}}$ & $7(41)$ & $2(15)^{\mathrm{a}}$ \\
\hline Mid face, $\mathrm{n}(\%)$ & $45(85)^{\mathrm{b}}$ & $22(96)^{\mathrm{a}}$ & $17(100)$ & $6(46)^{\mathrm{a}}$ \\
\hline Lower face, $\mathrm{n}(\%)$ & $41(77)^{\mathrm{c}}$ & $17(74)$ & $15(88)^{\mathrm{a}}$ & $9(69)^{\mathrm{b}}$ \\
\hline
\end{tabular}

Notes: Overall, one of the three areas was treated in $15(28 \%)$ patients, two areas were treated in $25(47 \%)$ patients, and all three areas were treated in $13(25 \%)$ patients. aln one patient, the filler was applied unilaterally. 'In two patients, the filler was applied unilaterally. 'In three patients, the filler was applied unilaterally.

Table 3 The volume of hyaluronic acid dermal filler injected per patient

\begin{tabular}{|c|c|c|c|c|}
\hline Injected volume in $\mathrm{mL}$ & $\begin{array}{l}\text { Overall } \\
(\mathrm{N}=53)\end{array}$ & $\begin{array}{l}\text { Facial lipoatrophy } \\
(\mathbf{N}=\mathbf{2 3})\end{array}$ & $\begin{array}{l}\text { Morphological asymmetry } \\
(\mathrm{N}=17)\end{array}$ & $\begin{array}{l}\text { Debilitating scars } \\
(\mathrm{N}=13)\end{array}$ \\
\hline Initial treatment $(\mathrm{mL})$, mean $(\mathrm{SD})$ [range] & $4.3(1.8)[2-7]$ & $4.6(1.2)[2-7]$ & $4.8(1.0)[3-6]$ & $3.1(1.2)[2-6]$ \\
\hline 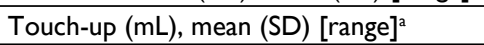 & $2.4(0.9)[0.5-4]$ & $2.7(0.7)[2-4]$ & $2.8(0.6)[2-4]$ & $\mathrm{I} .5(0.7)[0.5-3]$ \\
\hline Total $(\mathrm{mL})$, mean $(\mathrm{SD})$ [range] & $6.0(1.8)[2-9]$ & $6.4(1.6)[4-9]$ & $6.7(1.5)[3-9]$ & $4.4(1.8)[2-9]$ \\
\hline
\end{tabular}

Note: ${ }^{\top}$ Touch-up was performed in a total of 37 (67\%) patients: $15 / 23$ (65\%) patients with facial lipoatrophy, II/I7 (65\%) patients with asymmetry, and II//3 (85\%) patients with scars. 
A

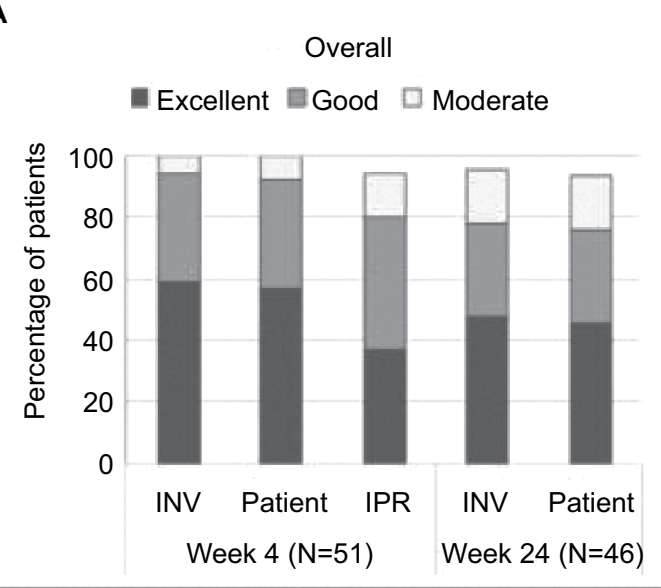

C

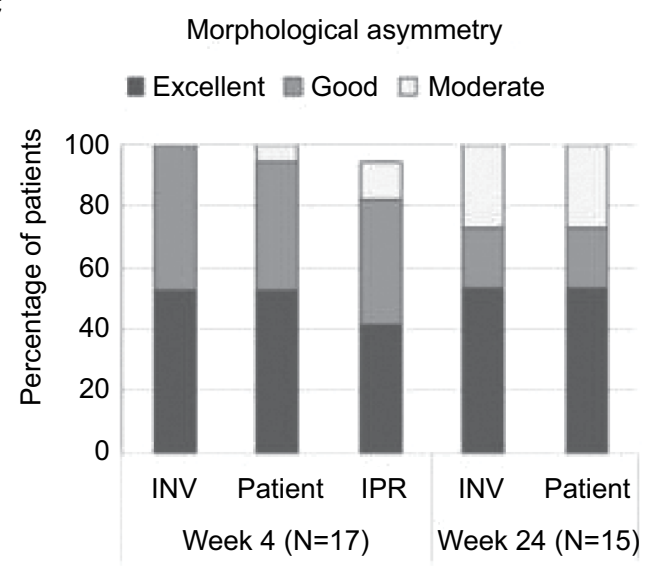

B

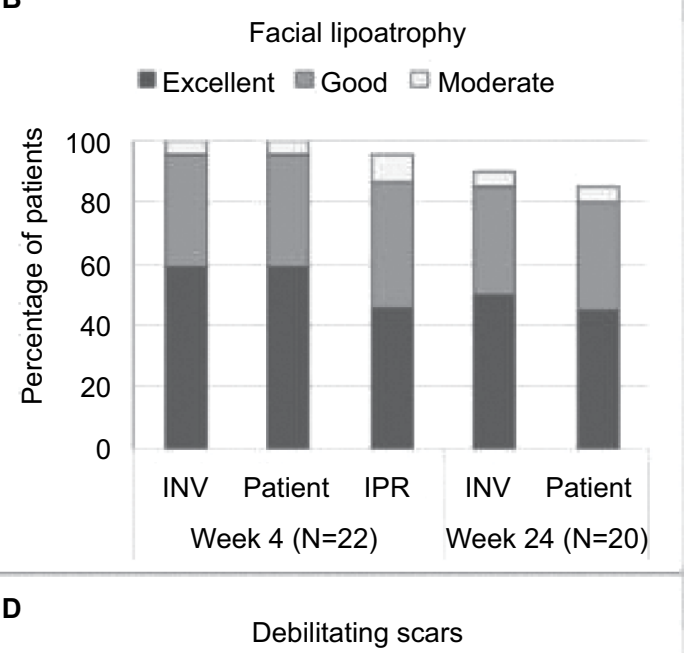

Excellent $\square$ Good $\square$ Moderate

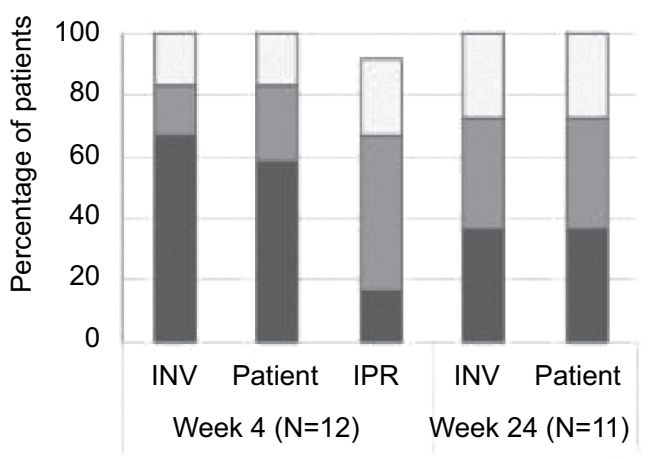

Figure I Success rates of treatment after administration of the hyaluronic acid dermal filler Princess ${ }^{\circledR}$ FILLER, overall and by indication (safety population, observed cases’ analysis).

Notes: Treatment outcome was evaluated by the INV, by the patient and, at Week 4, by the IPR. Success was defined as an excellent, good, or moderate correction of the defect. Worsening was not observed in any patient. (A) Overall Success Rate of treatment after administration. (B) Success Rate of treatment after administration in patients with facial lipoatrophy. (C) Success Rate of treatment after administration in patients with morphological asymmetry. (D) Success Rate of treatment after administration in patients with debilitating scars.

Abbreviations: INV, investigator; IPR, independent photography reviewer.

or virtual due to hyperplasia on contralateral side. While the cause of asymmetry may be known (eg, congenital anomaly, genetic disorder, trauma, infection, neoplasm, and other diseases of the facial structures), in many cases, it remains obscure. It is speculated that factors such as habitual mastication on one side and constant facial pressure exclusively on one side during sleep, deleterious oral habits, or unilateral crossbite may trigger the asymmetric development of facial structures, resulting in disharmony. ${ }^{18,19}$

Obtained results indicate that pathological deficits in facial or dermal volume can be successfully restored by the tested dermal filler, regardless of the cause or location. In investigator's opinion, the treatment was successful in all patients who attended Week 4 visit. Importantly, a complete or almost complete correction of the defect was achieved in $\sim 60 \%$ of the patients, with no major difference between the indications. In a further $35 \%$ of patients, a moderate response was observed in line with the expected outcome. Similar results were obtained when evaluation was based on the patient's self-assessment, corroborating the investigator's ratings. High treatment success rate was also confirmed by the independent review of patient photographs. In general, the assessments made by the independent reviewer were slightly more conservative than those made by both the investigator and the patients. This may be partly attributed to genuine limitation of photo review compared to live assessments, since it provides a restricted insight from few preselected perspectives only. With respect to the durability of therapeutic effect, in most patients ( $95 \%$ ), the effect was maintained for at least 6 months. Notably, at 6 months after the intervention, the effect was still graded as excellent or good in around $75 \%$ of the patients. 

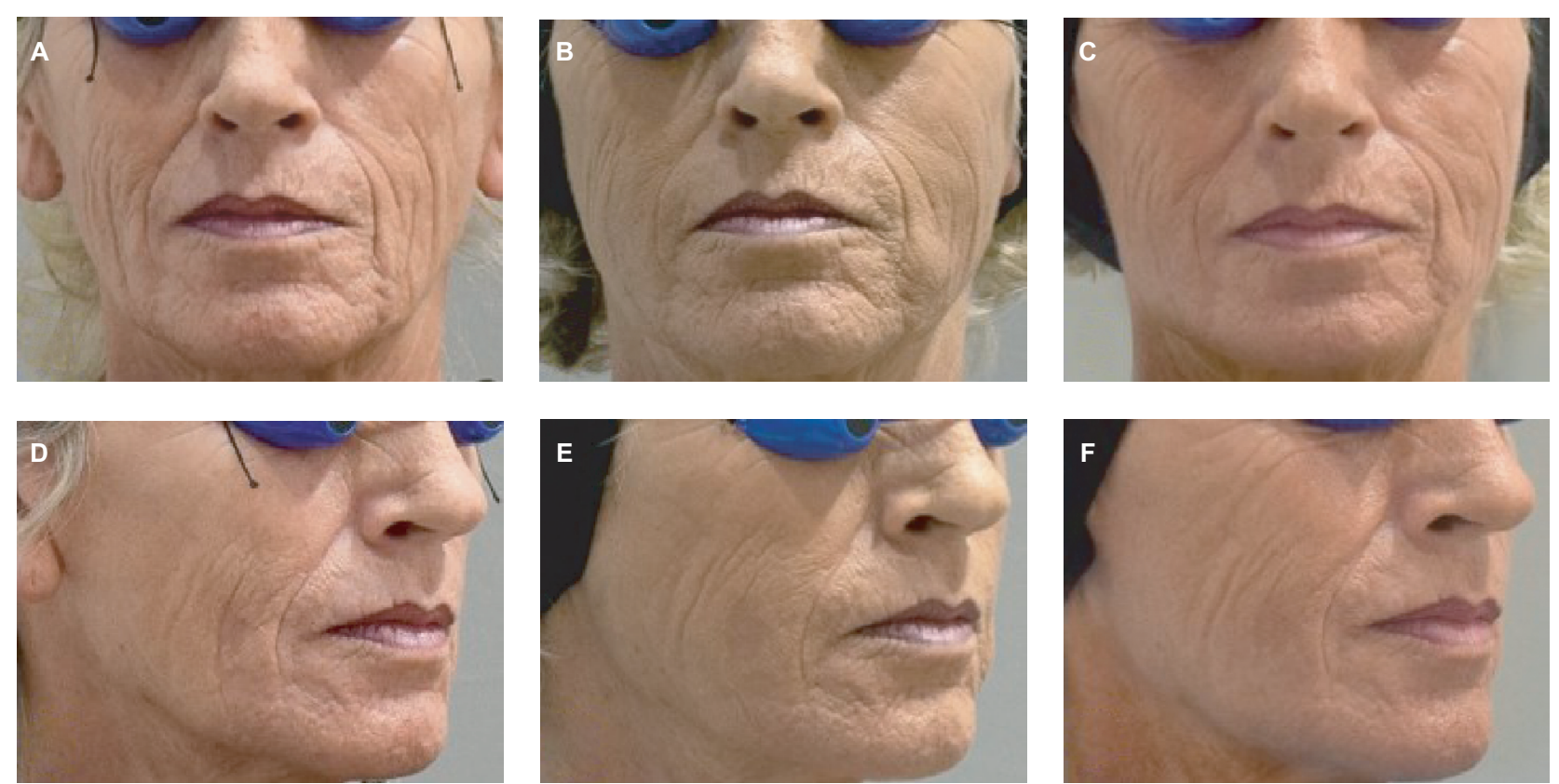

Figure 2 Facial lipoatrophy correction with hyaluronic acid dermal filler.

Notes: A 6I-year-old patient suffering from grade 2 facial lipoatrophy (Ascher's scale), before ( $\mathbf{A}$ and $\mathbf{D})$ and after the treatment at Week 4 (B and $\mathbf{E}$ ) and Week 24 (C and F). A total of $8 \mathrm{~mL}$ of the filler was injected into the midface: $6 \mathrm{~mL}$ on Day I and $2 \mathrm{~mL} 2$ weeks later for a touch-up on the left side.
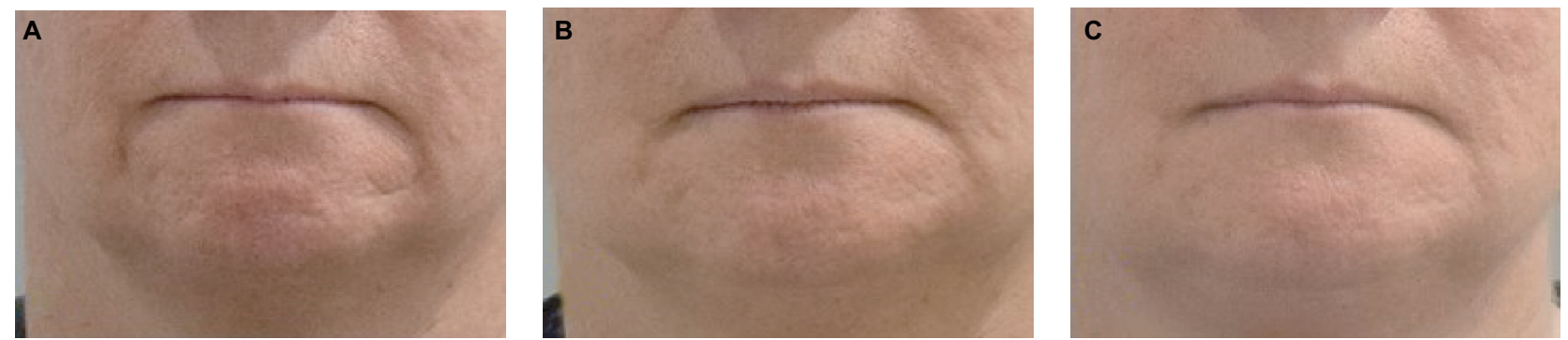

Figure 3 Scar correction with hyaluronic acid dermal filler.

Notes: A 49-year-old patient with atrophic scars on the chin, before (A) and after the treatment at Week 4 (B) and Week 24 (C). A total of $4.4 \mathrm{~mL}$ of the filler was injected into the lower face: $3.4 \mathrm{~mL}$ on Day I and I $\mathrm{mL} 2$ weeks later for a touch-up.

The effectiveness observed in patients with FLA was comparable to the effectiveness of other HA fillers, tested in patients with HIV-related lipoatrophy. The scales used across the studies were slightly different, but in general, the esthetic improvement rates at 6 months ranged from $90 \%$ to $100 \%{ }^{9-11,13}$ The frequency of side effects in the current study was lower than stated in the literature. In the present study, treatment-related adverse events were reported in four patients with FLA (18\%), compared to $29 \%-70 \%$ in other trials. ${ }^{9-13}$ Although none of our patients had a history of HIV, a higher incidence of side effects was more likely related to subcutaneous administration of the filler, which was driven by characteristics of the filler used. The average amount of the filler was similar across the studies, around $6 \mathrm{~mL}$ per patient, which is why this factor could be excluded as an explanation.

Regarding MA, most faces are asymmetric to a certain extent and the point at which "normal" asymmetry becomes "abnormal" cannot be easily defined. It often depends on the clinician's sense of balance and, more importantly, the patient's sense of imbalance. ${ }^{18}$ No details were collected on asymmetric anatomic landmarks, but in most patients, the filler was administered bilaterally, into the midface and one or both of remaining areas. Literature data on HA filler used for the correction of facial asymmetry are limited to several case reports and two series of seven to eight patients with upper eyelid asymmetry who were successfully treated with 

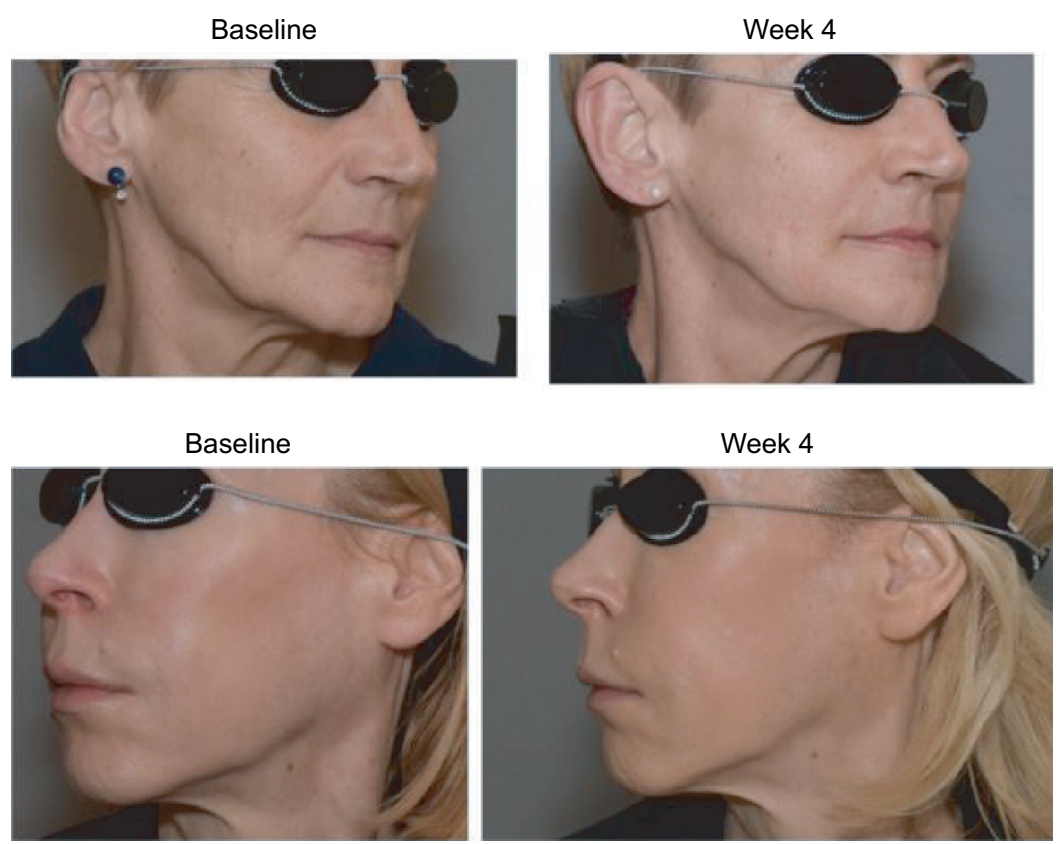

Figure 4 Additional examples of facial lipoatrophy correction with hyaluronic acid dermal filler.

Notes: Top: a 55-year-old patient suffering from grade 3 facial lipoatrophy (Ascher's scale), before (left) and after (right) the treatment at Week 4 . A total of $5 \mathrm{~mL}$ of the filler was injected into the upper, mid, and lower face (left and right) with no additional touch-up. Bottom: a 58-year-old patient suffering from grade 3 facial lipoatrophy (Ascher's scale), before (left) and after (right) the treatment at Week 4. A total of $5 \mathrm{~mL}$ of the filler was injected into the upper, mid, and lower face (left and right) with no additional touch-up.

HA. ${ }^{20,21}$ HA filler was also successfully used in combination with botulinum toxin to correct asymmetric periorbital features (nine patients), ${ }^{22}$ or functional asymmetry caused by hemifacial spasm (18 patients). ${ }^{23}$

The effectiveness and safety observed in patients with DS were consistent with data published by Hasson and Romero on a similar HA filler in 12 patients with atrophic scars of various origin. ${ }^{24}$ The effectiveness of HA in the treatment of scars was also conveyed in three small studies (5-12 patients each) on the HA treatment of atrophic acne scars by vertical filler technique, ${ }^{25}$ microinjection, ${ }^{26}$ or pneumatic injection, ${ }^{27}$ in a study in 15 patients with cicatricial ectropion, where HA was injected into the lower lid to stretch the tethered skin and correct the $\operatorname{lid}^{28}$ and several case reports.

\section{Conclusion}

Dermal filling with cross-linked HA is a viable treatment option for the correction of various soft tissue defects of the face resulting from FLA, MA, or depressed scars. The filler used in the present study, Princess ${ }^{\circledR}$ FILLER, was well-tolerated by patients, safe, and highly effective, with an overall treatment success rate of $94 \%-100 \%$, depending on the evaluator. In most patients, the response was sustained over 6 months after the treatment.

\section{Disclosure}

Zrinka Ivezic-Schoenfeld, Ira G Federspiel, and Martin Prinz are employees of Croma-Pharma $\mathrm{GmbH}$, which sponsored the present study. Daisy Kopera, Doris Grablowitz, and Benjamin Gehl served as investigators for Croma-Pharma $\mathrm{GmbH}$. The authors report no other conflicts of interest in this work.

\section{References}

1. American Society for Aesthetic Plastic Surgery [homepage on the Internet]. Cosmetic Surgery National Data Bank Statistics; 2016. Available from: https://www.surgery.org/media/statistics. Accessed December 12, 2017.

2. Cohen JL, Dayan SH, Brandt FS, et al. Systematic review of clinical trials of small- and large-gel-particle hyaluronic acid injectable fillers for aesthetic soft tissue augmentation. Dermatol Surg. 2013;39(2):205-231.

3. Fallacara A, Manfredini S, Durini E, Vertuani S. Hyaluronic acid fillers in soft tissue regeneration. Facial Plastic Surgery. 2017;33(01):087-096.

4. Leclercq P, Goujard C, Duracinsky M, et al. High prevalence and impact on the quality of life of facial lipoatrophy and other abnormalities in fat tissue distribution in HIV-infected patients treated with antiretroviral therapy. AIDS Res Hum Retroviruses. 2013;29(5):761-768.

5. Shackelford TK, Larsen RJ. Facial asymmetry as an indicator of psychological, emotional, and physiological distress. J Pers Soc Psychol. 1997;72(2):456-466.

6. Brown BC, McKenna SP, Siddhi K, McGrouther DA, Bayat A. The hidden cost of skin scars: quality of life after skin scarring. J Plast Reconstr Aesthet Surg. 2008;61(9):1049-1058.

7. Szczerkowska-Dobosz A, Olszewska B, Lemańska M, Purzycka-Bohdan D, Nowicki R. Acquired facial lipoatrophy: pathogenesis and therapeutic options. Postepy Dermatol Alergol. 2015;32(2):127-133. 
8. Forbat E, Ali FR, Al-Niaimi F. The role of fillers in the management of acne scars. Clin Exp Dermatol. 2017;42:374-380.

9. Bugge H, Negaard A, Skeie L, Bergersen B. Hyaluronic acid treatment of facial fat atrophy in HIV-positive patients. HIV Med. 2007;8(8):475-482.

10. Denton AB, Tsaparas Y. Injectable hyaluronic acid for the correction of HIV-associated facial lipoatrophy. Otolaryngol Head Neck Surg. 2007;136(4):563-567.

11. Bechara FG, Gambichler T, Brockmeyer NH, Sand M, Altmeyer P, Hoffmann K. Hyaluronic acid new formulation: experience in HIVassociated facial lipoatrophy. Dermatology. 2008;217(3):244-249.

12. Pignatti M, Pedone A, Baccarani A, et al. High-density hyaluronic acid for the treatment of HIV-related facial lipoatrophy. Aesthetic Plast Surg. 2012;36(1):180-185.

13. Ho D, Jagdeo J. Safety and efficacy of a volumizing hyaluronic acid filler for treatment of HIV-associated facial lipoatrophy. JAMA Dermatol. 2017;153(1):61-65.

14. Kablik J, Monheit GD, Yu L, Chang G, Gershkovich J. Comparative physical properties of hyaluronic acid dermal fillers. Dermatol Surg. 2009;35(Suppl 1):302-312.

15. Ascher B, Coleman S, Alster T, et al. Full scope of effect of facial lipoatrophy: a framework of disease understanding. Dermatol Surg. 2006;32(8):1058-1069.

16. Clopper CJ, Pearson ES. The use of confidence or fiducial limits illustrated in the case of the binomial. Biometrika. 1934;26(4):404-413.

17. Fabbrocini G, Annunziata MC, D'Arco V, et al. Acne scars: pathogenesis, classification and treatment. Dermatol Res Pract. 2010;2010:893080-13.

18. Cheong YW, Lo LJ, Lj L. Facial asymmetry: etiology, evaluation, and management. Chang Gung Med J. 2011;34(4):341-351.
19. Thiesen G, Gribel BF, Freitas MP. Facial asymmetry: a current review. Dental Press J Orthod. 2015;20(6):110-125.

20. Choi HS, Whipple KM, Oh SR, et al. Modifying the upper eyelid crease in Asian patients with hyaluronic acid fillers. Plast Reconstr Surg. 2011;127(2):844-849.

21. Mancini R, Khadavi NM, Goldberg RA. Nonsurgical management of upper eyelid margin asymmetry using hyaluronic acid gel filler. $O p h-$ thalmic Plast Reconstr Surg. 2011;27(1):1-3.

22. Berros P, Tsirbas A, Garcia P, Farhi D, Bétis F, Galatoire O. Oculofacial contour asymmetries: management of combined treatment with hyalurostructure and botulinum toxin injections. J Cosmet Laser Ther. 2012;14(2):111-116.

23. Borodic GE. Use of fillers as adjunct therapy for the treatment of lower face hemifacial spasm. Ophthalmic Plast Reconstr Surg. 2013;29(3): 225-226.

24. Hasson A, Romero WA. Treatment of facial atrophic scars with Esthélis, a hyaluronic acid filler with polydense cohesive matrix (CPM).J Drugs Dermatol. 2010;9(12):1507-1509.

25. Goodman GJ, Van Den Broek A. The modified tower vertical filler technique for the treatment of post-acne scarring. Australas J Dermatol. 2016;57(1):19-23.

26. Halachmi S, Ben Amitai D, Lapidoth M. Treatment of acne scars with hyaluronic acid: an improved approach. J Drugs Dermatol. 2013;12(7): e121-123.

27. Lee JW, Kim BJ, Kim MN, Lee CK. Treatment of acne scars using subdermal minimal surgery technology. Dermatol Surg. 2010;36(8):1281-1287.

28. Fezza JP. Nonsurgical treatment of cicatricial ectropion with hyaluronic acid filler. Plast Reconstr Surg. 2008;121(3):1009-1014.
Clinical, Cosmetic and Investigational Dermatology

\section{Publish your work in this journal}

Clinical, Cosmetic and Investigational Dermatology is an international, peer-reviewed, open access, online journal that focuses on the latest clinical and experimental research in all aspects of skin disease and cosmetic interventions. This journal is included on PubMed. The manuscript management system is completely online

\section{Dovepress}

and includes a very quick and fair peer-review system, which is all easy to use. Visit http://www.dovepress.com/testimonials.php to read real quotes from published authors 